\title{
Assessing Prognosis of Acute Coronary Syndrome in Recent Clinical Trials: A Systematic Review
}

\author{
Fan Ye, MD; David Winchester, MD; Michael Jansen, MD; Arthur Lee, MD; Burton Silverstein; Carolyn Stalvey, MD; \\ Matheen Khuddus, MD; Joseph J. Mazza, MD; and Steven H. Yale, MD
}

\begin{abstract}
There is no recent comprehensive overview of contemporary clinical trials assessing short and longterm outcomes in patients with acute coronary syndrome (ACS). This paper reviews factors from recent clinical trials that influenced prognosis in patients with ACS. Cochrane and PubMed databases were screened systematically for clinical trials published in the English literature reporting on ACS prognosis. Two authors independently screened titles, abstracts, and full text. Studies meeting inclusion criteria evaluated the impact of modern practice on prognosis. In vitro and animal models studies, conference abstracts, imaging studies, and review articles were excluded. Disagreement in inclusion criteria was resolved by consensus. A large study of 8,859 patients showed no difference in all-cause mortality between $3 \mathrm{I}$ days and 2 years in patients with ST segment elevation myocardial infarction (STEMI) compared to those with non-ST segment elevation myocardial infarction (NSTEMI) or stable ischemic heart disease (SIHD). Other studies showed a significant increase in all-cause mortality in patients with STEMI within the first 30 days, with NSTEMI patients exhibiting a higher mortality rate compared to those with SIHD during the 2-year follow-up period. Our review found that women have a poorer short-term prognosis compared to men. Additionally, reports from patients receiving comprehensive and coordinated care showed longer survival rates. In view of the improved prognosis demonstrated for patients suffering from ACS, assessing prognosis in patients represents a formidable task in modern practice. Our review highlights the need for further evidence-based studies evaluating long-term outcomes on diagnostic and treatment strategies.
\end{abstract}

Keywords: Angina; Cardiovascular disease; Clinical trial; Heart failure;

Patient outcomes; Prognosis; Review; Systematic

A cute coronary syndrome (ACS) is a common flowlimiting disease of the coronary arteries caused by a supply-demand mismatch in myocardial perfusion. ${ }^{1}$ It is a disabling medical condition that affects 112 million people over the age of 20 years worldwide. ${ }^{2}$ Though the mortality of patients with ACS has declined in recent years, ischemic heart disease remains the leading cause of deaths (45.1\%, nearly 801,000 deaths) attributable to cardiovascular disease in the United States, and it is associated with enormous healthcare costs. Patients with ACS often experience limitations in ordinary activities, other co-morbidities, and mental health issues that impair quality of life $(\mathrm{QoL})$. The therapeutic goal is directed towards relieving symptoms and improving functional status as well as the patient's selfperception of their health or QoL. Current management

Corresponding Author: Steven H. Yale, MD, Department of Internal Medicine, University of Central Florida College of Medicine, Lake Nona, Blvd, Orlando, FL 32877. Tel: (7I5) 383-0928, Email: steven.yale.md@gmail.com. strategies for ACS include pharmacologic therapy, invasive interventional techniques, and life style modification. These treatment options are complementary rather than mutually exclusive.

There has been a rapid and significant improvement in prognosis of patients with ACS due to advancements in drug therapy and interventional techniques. Despite recent advances in treatment, mortality remains substantially high after hospital admission. Prognosis in patients with ACS, with or without heart failure, has been shown to differ based on a medical or revascularization approach and modified by factors including sex differences, physical activity, follow-up strategies, medications, and concomitant heart failure.

\section{Received:April 4, 2018}

Ist Revision: October 21, 2018

2nd Revision: January 22, 2019

3rd Revision: March II, 2019

Accepted: March 18, 2019 
Table 1. Descriptive information of the included randomized controlled trials (RCTs) and subjects in this review

\begin{tabular}{|c|c|c|c|c|c|c|c|}
\hline & Trial type & $\begin{array}{l}\text { Year of } \\
\text { publication }\end{array}$ & Trial name & $\begin{array}{l}\text { Number } \\
\text { of } \\
\text { patients }\end{array}$ & Study sites & $\begin{array}{l}\text { Age } \\
\text { (mean, } \\
\text { years) }\end{array}$ & $\begin{array}{l}\text { Male } \\
\text { percentage } \\
\text { (median) }\end{array}$ \\
\hline 1 & $\mathrm{RCT}$ & $\begin{array}{l}\text { 2012, } \\
\text { (Ref 3) }\end{array}$ & $\begin{array}{l}\text { HORIZONS- } \\
\text { AMI }\end{array}$ & 2849 & 11 countries & 60 & NA \\
\hline 2 & $\begin{array}{l}\text { RCT, double } \\
\text { blind }\end{array}$ & $\begin{array}{l}\text { 2013, } \\
\text { (Ref 4) }\end{array}$ & SATURN & 1039 & One site & 57.6 & $73.6 \%$ \\
\hline 3 & $\mathrm{RCT}$ & $\begin{array}{l}\text { 2013, } \\
\text { (Ref 5) }\end{array}$ & & 115 & $\begin{array}{l}\text { eight primary } \\
\text { care centers of } \\
\text { the Spanish }\end{array}$ & 55 & $82 \%$ \\
\hline 4 & $\mathrm{RCT}$ & $\begin{array}{l}2014, \\
\text { (Ref 6) }\end{array}$ & CRISP & 523 & $\begin{array}{l}40 \text { centers, } 20 \\
\text { in the UK and } \\
20 \text { overseas }\end{array}$ & 76 & $78 \%$ \\
\hline 5 & $\mathrm{RCT}$ & $\begin{array}{l}2014, \\
\text { (Ref 7) }\end{array}$ & & 253 & $\begin{array}{l}4 \text { VA medical } \\
\text { centers within } \\
\text { USA }\end{array}$ & 63.8 & $97 \%$ \\
\hline 6 & $\mathrm{RCT}$ & $\begin{array}{l}\text { 2016, } \\
\text { (Ref 8) }\end{array}$ & $5 \mathrm{RCTs}$ & 8859 & $\begin{array}{l}\text { Multicenter, } \\
\text { internationally }\end{array}$ & $62-66$ & $75-78 \%$ \\
\hline 7 & $\mathrm{RCT}$ & $\begin{array}{l}\text { 2016, } \\
\text { (Ref 9) }\end{array}$ & HF-ACTION & 2331 & $\begin{array}{l}\text { Multicenter } \\
\text { United States, } \\
\text { Canada, and } \\
\text { France }\end{array}$ & $59-60$ & $71-73 \%$ \\
\hline 8 & $\mathrm{RCT}$ & $\begin{array}{l}\text { 2016, } \\
\text { (Ref 10) }\end{array}$ & & 932 & Single center & 61 & $71-73 \%$ \\
\hline 9 & $\mathrm{RCT}$ & $\begin{array}{l}\text { 2016, } \\
\text { (Ref 11) }\end{array}$ & & 979 & $\begin{array}{l}\text { A single center, } \\
\text { China }\end{array}$ & 60.35 & $73 \%$ \\
\hline 10 & $\begin{array}{l}\text { Randomized, } \\
\text { active- } \\
\text { controlled and } \\
\text { end point- } \\
\text { blinded study. }\end{array}$ & $\begin{array}{l}\text { 2016, } \\
\text { (Ref 12) }\end{array}$ & & 172 & Single center & 59 & $78-84 \%$ \\
\hline 11 & $\begin{array}{l}\text { Double-blind, } \\
\text { placebo- } \\
\text { controlled, } \\
\text { event-driven } \\
\text { randomized } \\
\text { trial }\end{array}$ & $\begin{array}{l}\text { 2016, } \\
\text { (Ref 13) }\end{array}$ & & 2651 & $\begin{array}{l}245 \text { centers in } \\
15 \text { countries in } \\
\text { Europe, Israel, } \\
\text { Russia and the } \\
\text { USA }\end{array}$ & 63.4 & $79 \%$ \\
\hline
\end{tabular}

Regardless of the approach, treatment goals should be directed towards improving survival and QoL.

There is no recent comprehensive overview of contemporary clinical trials assessing factors on outcomes in patients with ACS. We hypothesized that ACS mortality is influenced by a variety of factors including sex, exercise, medications, and type of follow-up. The aim of this study was to systematically review recent (2012-2017) evidence-based management strategies from randomized and observational studies using the Preferred Reporting Items for Systematic Reviews and Meta-Analyses (PRISMA) method to critically appraise relevant papers in this systematic review.

\section{Methods}

Search Strategy

Cochrane and PUBMED database were searched using the medical subject headings (MeSH) terms: prognosis, angina, 
and clinical trials. The search was limited to human clinical trials in the English literature published from January 1, 2012 to October 31, 2017. The bibliographies of retrieved articles were reviewed for additional relevant studies.

\section{Eligibility Criteria}

Two authors independently screened titles, abstracts, and full text for potentially eligible articles. Studies chosen were those that evaluated the impact of modern practice on the prognosis of patients with ACS. In vitro and animal models studies, conference abstracts, imaging studies, and review articles were excluded. Disagreement in inclusion criteria was resolved by consensus.

\section{Data Extraction and Quality Assessment}

This systematic review was performed following the PRISMA method. The authors, journal, year of publication, study location, treatment, and outcomes were abstracted. Two authors reviewed all included studies independently in order to minimize risk of bias across studies (ie, publication bias, selective reporting).

\section{Results}

\section{Study Identification}

Initial screen yielded 120 relevant citations appraised at the title and abstract level, 64 of which were removed (51 based on research scope and 13 that were reviews and conference reports); another 21 studies were discarded after reviewing the abstract (18 based on research scope and 3 were review articles). The full text was reviewed for the 35 remaining articles. Based on that review, 13 papers were excluded, since the articles were related to biomarkers and assessment tools.
Thus, 22 studies constituted our final publication set included in this review (Figure 1).

\section{Study Characteristics}

Fifteen studies were randomized controlled trials (RCTs), with a total of 20,703 patients (mean age ranging from 55 to 76 years) with ACS (Table 1). Two of the RCTs were doubleblind placebo-controlled studies (Table 1). Four of the fifteen studies were sub-analyses of RCTs (Table 2), and the remaining seven were cohort and observational studies (median sample size ranging from 81 to 10,003 , mean age ranging from 54 to 70 years) (Tables 3 and 4). The duration of follow-up varied from 4 weeks to 56 months. Cardiac death, all-cause death, and major adverse cardiovascular events (MACEs) were the most commonly measured outcomes. Descriptive information of the included trials and subjects in this review is summarized in Tables 1-4.

\section{Study Quality}

Among all studies included in this review, only 10 reported detailed methods, and no study reported methods used for determining sample size calculations, allocation concealment, or blinding methods. For those studies reporting follow-up (Table 1, studies 3-11), all reported a high follow-up rate (95\%-99\%), but no explanation was given for the reasons for dropouts. The characteristics of participants in each study arm were similar at baseline (age, race, sex, and disease course)

\section{Mortality}

Pilgrim et $\mathrm{al}^{8}$ reported a significant increase in all-cause mortality in patients with ST segment elevation myocardial infarction (STEMI) within the first 30 days. No difference in

Table 2. Descriptive information of the included randomized controlled trial (RCT) subanalysis and subjects in this review.

\begin{tabular}{|c|c|c|c|c|c|c|c|}
\hline & Trial type & $\begin{array}{l}\text { Year of } \\
\text { publication }\end{array}$ & $\begin{array}{l}\text { Trial name } \\
\text { (sub- } \\
\text { analysis) }\end{array}$ & $\begin{array}{l}\text { Number } \\
\text { of } \\
\text { patients }\end{array}$ & Study sites & $\begin{array}{l}\text { Age } \\
\text { (mean, } \\
\text { years) }\end{array}$ & $\begin{array}{l}\text { Male } \\
\text { percentage } \\
\text { (median) }\end{array}$ \\
\hline 1 & $\mathrm{RCT}$ & $\begin{array}{l}2015, \\
\text { (Ref 14) }\end{array}$ & STICH & 1212 & Multicenter. & $59-61$ & $88-89 \%$ \\
\hline 2 & $\begin{array}{l}\text { Randomized, } \\
\text { double blind, } \\
\text { placebo } \\
\text { controlled trial }\end{array}$ & $\begin{array}{l}2015, \\
\text { (Ref 15) }\end{array}$ & TOPCAT & 3400 & $\begin{array}{l}\text { United States, } \\
\text { Canada, } \\
\text { Russia, } \\
\text { Republic of } \\
\text { Georgia, } \\
\text { Brazil, and } \\
\text { Argentina }\end{array}$ & 65.8 & $50 \%$ \\
\hline 3 & $\mathrm{RCT}$ & $\begin{array}{l}2016, \\
\text { (Ref 16) }\end{array}$ & $\begin{array}{l}\text { BASKET- } \\
\text { PROVE }\end{array}$ & 2314 & $\begin{array}{l}\text { Switzerland, } \\
\text { Denmark, } \\
\text { Austria, and } \\
\text { Italy }\end{array}$ & 66 & $74-76 \%$ \\
\hline 4 & $\mathrm{RCT}$ & $\begin{array}{l}\text { 2016, } \\
\text { (Ref 17) }\end{array}$ & $\begin{array}{l}\text { HIJCREATE } \\
\text { Trial }\end{array}$ & 1849 & Japan & 64 & $80 \%$ \\
\hline
\end{tabular}




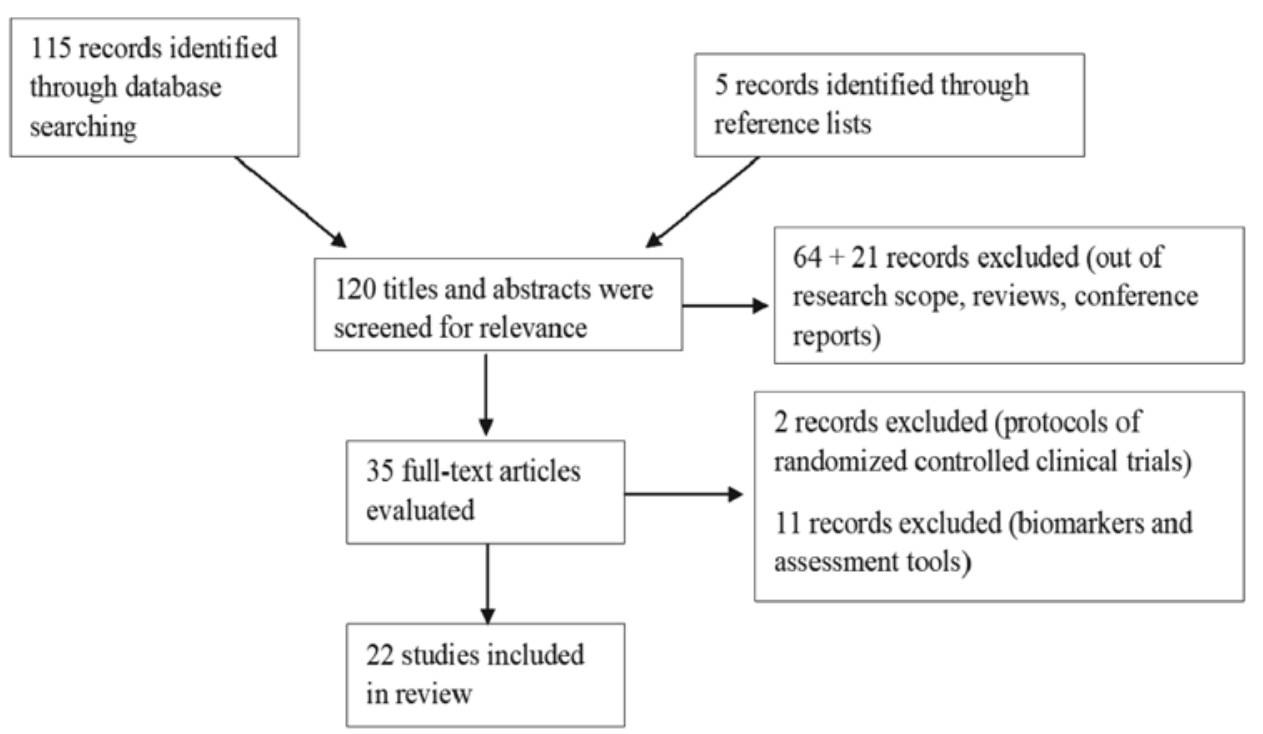

Figure 1. Flow chart of literature review and analysis

all-cause mortality was found between 31 days and 2 years in patients with STEMI. In contrast, patients with non-ST segment elevation myocardial infarction (NSTEMI) exhibited a higher mortality rate compared to those with stable ischemic heart disease (SIHD) at 2 years' follow-up. ${ }^{8}$ Interestingly, the prevalence of cardiovascular risk factors and frequency of prior cardiovascular disease incidence remained lower in patients with STEMI compared to those with NSTEMI, SIHD, and recurrent myocardial infarction (MI) at 2 years of follow up. ${ }^{8}$

For patients who underwent percutaneous coronary intervention (PCI) procedures, mortality and MACE rates were higher among patients in the urgent PCI group during hospitalization. ${ }^{24}$ No differences were reported by Yao et $\mathrm{al}^{24}$ after hospital discharge within the urgent PCI, delayed PCI, NSTEMI, and SIHD groups. Patients who received paclitaxeleluting stents (PES) had a higher rate of cardiac death and MI compared to sirolimus-eluting stent (SES) (observational registry). ${ }^{24}$ Further evidence showed that patients with a higher clinical cardiovascular risk benefited from drug eluting stents (DES) (lower death rates from cardiac causes), whereas no difference in mortality was seen between DES and bare metal stents (BMS) in patients with low to moderate risks (BASKET-PROVE trial) ${ }^{16}$ Patients who underwent coronary artery bypass grafting $(\mathrm{CABG})$ were more likely to report improvement in angina symptoms compared to those who received medical therapy alone (odds ratio: $0.70 ; 95 \% \mathrm{CI}$ : 0.55 to $0.90 ; P<0.01) .{ }^{16}$

\section{Angina Pectoris in Heart Failure Patients}

No correlation was found between resolution of angina symptoms and all-cause mortality in medically treated patients with left ventricular (LV) dysfunction and coronary artery disease (CAD) (STICH trial). ${ }^{14}$ Nearly every trial found that reduced LV function was associated with worse QoL and mental health issues such as depression. Among patients with heart failure with reduced ejection fraction, an increased rate of hospitalization was found ( $71.2 \%$ vs. $62.3 \%$; hazard ratio 1.25 ; $P=0.003$; HF-ACTION trial) ${ }^{9}$, whereas no difference in all-cause or CV mortality at follow-up was observed $(16.3 \%$ vs. $16.7 \%$; hazard ratio $0.88 ; P=0.39$; HF-ACTION trial). ${ }^{9} \mathrm{~A}$ "J-shaped phenomenon on blood pressure" was observed only in the preserved left ventricular ejection fraction (LVEF) group, which suggested that excessive blood pressure control had no impact on MACE in CAD patients with hypertension and reduced LVEF (HIJCREATE trial). ${ }^{17}$ Patients with angina pectoris and preserved ejection fraction had higher rate of impaired QoL, with depression being more prevalent in younger patients $(43 \%$ age $<60$ vs. $57 \%$ age $>60 ; P<0.01$; HF-ACTION trial). ${ }^{15}$

\section{Other Characteristics}

Sex differences

Studies showed that although women had lower rates of CAD compared to men, they were more likely to have certain cardiovascular risk factors including hypertension ( $66.6 \% \mathrm{vs}$. $63.2 \% ; P<0.005)$, dyslipidemia (68.9\% vs. $66.3 \%: P<0.005)$, and a family history of premature CAD, especially when older ( $>60$ years-of-age; $34.6 \%$ vs. $29.3 \% ; P<0.005$ ). ${ }^{20}$ Women were also less likely to have a positive stress test $(9.7 \%$ vs. $15.1 \%$; $P<0.001$; PROMISE trial). ${ }^{20}$

\section{Exercise}

A cycle ergometer exercise program supervised by primary care nurses increased the functional capacity of coronary patients more than unsupervised walking (ESCAP trial). ${ }^{5}$ Despite greater peak improvement in $\mathrm{VO}_{2}$ (interaction $P$ value between baseline angina and treatment group, $P=0.02$ ) with exercise training, patients with angina pectoris with reduced ejection fraction experienced more adverse outcomes $(73.9 \%$ vs. $65.2 \%$; hazard ratio $1.22 ; P=0.01$; HF-ACTION trial). ${ }^{9}$

\section{Follow-up Strategies}

Patients followed up by a comprehensive team consisting of pharmacist, patient education, primary care physicians, and 
Table 3. Descriptive information of the included cohort studies and subjects in this review.

\begin{tabular}{|c|c|c|c|c|c|c|c|}
\hline & $\begin{array}{l}\text { Trial type } \\
\text { (Cohort) }\end{array}$ & $\begin{array}{l}\text { Year of } \\
\text { publication }\end{array}$ & Trial name & $\begin{array}{l}\text { Number } \\
\text { of } \\
\text { patients }\end{array}$ & Study sites & $\begin{array}{l}\text { Age } \\
\text { (mean, } \\
\text { years) }\end{array}$ & $\begin{array}{l}\text { Male } \\
\text { percentage } \\
\text { (median) }\end{array}$ \\
\hline 1 & Prospective & $\begin{array}{l}\text { 2013, } \\
\text { (Ref 18) }\end{array}$ & & 81 & $\begin{array}{l}\text { Pusan National } \\
\text { University } \\
\text { Hospital }\end{array}$ & $\begin{array}{l}65.3- \\
66.2\end{array}$ & $48.8-62.5 \%$ \\
\hline 2 & Prospective & $\begin{array}{l}\text { 2015, } \\
\text { (Ref 19) }\end{array}$ & & 100 & China & 62 & $\begin{array}{l}\text { More male } \\
31 / 48 \text { and } \\
28 / 43\end{array}$ \\
\hline 3 & Prospective & $\begin{array}{l}2016, \\
\text { (Ref 20) }\end{array}$ & $\begin{array}{l}\text { PROMISE } \\
\text { sub- } \\
\text { analysis }\end{array}$ & 10003 & North America & $59-62$ & $47 \%$ \\
\hline 4 & Retrospective & $\begin{array}{l}2017, \\
\text { (Ref 21) }\end{array}$ & & 1270 & $\begin{array}{l}\text { Multicenter, } \\
\text { internationally }\end{array}$ & 70 & $66-77 \%$ \\
\hline
\end{tabular}

cardiologist were more likely to adhere to medical therapy (multi-faceted, patient-centered intervention study). ${ }^{7}$ The proportions of all-cause death, cardiac death, and cumulative MACEs of patients in the intensive follow-up group were reportedly lower than the control group: these patients had a longer survival (log rank $=8.565 ; P=0.003)$, lower medical costs (US $\$ 582.74$ vs. US $\$ 999.32 ; P=0.003$ ), better control of cardiovascular risk factors, and medication adherence. ${ }^{11}$ According to an observational registry study, independent predictors of death during follow-up were age (HR 1.03: $P<0.001$ ), left ventricular ejection function $<40 \%$ (HR 2.79; $P=0.002$ ), diabetes mellitus (HR 2.38; $P=0.007$ ), prior coronary artery bypass graft (HR $13.9 ; P=0.001)$ and chronic total occlusion (HR 2.93; $P=0.003$; observational registry). ${ }^{24}$

\section{Medications}

The incidence of ischemia-driven revascularization or hospitalization in patients with a history of CAD showed no significant differences between ranolazine and placebo. ${ }^{13}$ Ranolazine did not reduce the frequency of sudden cardiac death, cardiovascular death, and MI (RIVER-PCI trial). ${ }^{13}$ Based on laboratory and imaging results (post-PCI peak creatine kinase-MB, troponin I levels, site branch occlusion, or flow reduction), no benefits were observed with intracoronary nicorandil infusion. ${ }^{18}$ Some Chinese herbals such as Dan-hong, were shown to decrease inflammatory or necrosis markers (Scd40L) and improved cardiac function. ${ }^{19}$

Dual antiplatelet therapy is standard treatment after PCI. Prasugrel exhibited higher inhibition on platelet reactivity than double-dose clopidogrel, but no difference was observed on the rate of MACEs at follow-up in the TAILOR trial (median of 571 days, myocardial infarction $3.7 \%$ vs. $3.8 \%$, $P=1$; stroke $1.9 \%$ vs. $0 \%, P=1$; CV death $3.7 \%$ vs. $9.6 \%$, $P=0.27) .{ }^{23}$ The incidence of MACEs at 12-month follow up was lower in patients given nebivolol (10 mg daily) compared to the metoprolol group (200 $\mathrm{mg}$ once daily) (14.5\% vs. $31.5 \% ; P=0.03$ ), but no difference was observed between nebivolol and the carvedilol group (25 mg twice daily; $20.3 \%$
vs.31.5\%,P>0.05) or between carvedilol and the metoprolol succinate groups $(14.5 \%$ vs. $20.3 \%, P>0.05) .{ }^{12}$

Though more adverse effects have been related to highintensity statin therapy, it has been shown to be more effective than moderate-intensity statin therapy in reducing MACE rate at follow up in patients with ACS (16.8\% vs. $10.1 \%$, $P=0.021) .{ }^{10}$ Patients with percent atheroma volume (PAV) had a higher cumulative incidence of MACEs in 2 years of followup compared with all lower PAV quartiles combined $(12 \%$, log-rank test $P=0.001$, SATURN study). ${ }^{4}$

\section{Discussion}

This systematic review from 2012 to 2017 was undertaken to gain insight into recent developments on the prognosis of patients with ACS (Table 5). Our review included evaluation of medical and interventional treatments in patients with ACS. Consistent with the results of studies conducted prior to $2012,{ }^{25-27}$ our review shows that patients with STEMI remain at higher risk for all-cause mortality during short-term followup. However, no difference in prognosis was found beyond the first 30 days in STEMI, NSTEMI, or SIHD patients. Additionally, NSTEMI patients were more likely than those with SIHD to have a higher mortality rate regardless of their clinical presentation. Furthermore, patients with NSTEMI had a poorer long-term prognosis compared to SIHD.

The finding of a high cardiac mortality in NSTEMI patients was not unexpected, and several factors may account for the adverse prognosis. A higher mortality during hospitalization and short-term follow up may be explained by age-based variation in ACS. STEMI patients are typically younger and have fewer comorbidities and other cardiac "warning signs" before the onset. NSTEMI and SIHD patients are older and have more advanced CAD. It seems plausible that the variability found between STEMI and NSTEMI or SIHD patients could be attributed, partially, to STEMI patients receiving guideline-recommended pharmacotherapy more often as well as close long-term follow up medical care. ${ }^{27}$ 
STEMI patients also receive more stringent secondary prevention and standard interventions that may further reduce the risk for adverse late-term outcomes. ${ }^{28}$ This raises a valuable question of whether interventional or revascularization procedures should be considered in patients with NSTEMI to identify and treat culprit stenosis and to prevent further inflammatory progression of non-culprit lesions. Indeed, cardiovascular events occurring during follow up after percutaneous coronary intervention are equally attributable to recurrence at the site of culprit lesions and nonculprit lesions, the latter may occur do to activation of chronic inflammatory disease process. ${ }^{28-30}$

Our systematic review reveals that prognosis in patients treated medically is non-inferior to interventional therapies, although the latter is effective in reducing the frequency of recurrent angina symptoms. CABG has been shown to improve symptoms without effecting prognosis in patients with angina pectoris. In fact, in-hospital and short-term outcomes are generally favorable in CABG and NSTEMI patients. Additionally, urgent PCI is associated with higher in-hospital mortality. Consequently, our review reconfirms prior studies that CABG or PCI may not be the preferred treatment for low- to moderate-risk patients, and stenting in selected patients may be beneficial for improving angina symptoms. In the majority of patients, pharmacological treatment is successful in relieving symptoms, whereas in patients with STEMI, surgical treatment appears to be more effective in controlling symptoms than invasive procedures without affecting prognosis.

Heart failure was found to be associated with higher mortality, and the strongest independent risk factor for mortality reported was reduced left ventricular ejection fraction. ${ }^{31}$ Nonetheless, over the last three decades, in-hospital and 30-day mortality have markedly decreased presumably due to improved acute management of MI. ${ }^{32}$ Heart failure is a potentially debilitating complication of ischemic heart disease. As illustrated from our results, heart failure is also an important predictor for long-term prognosis. It is vital to diagnose heart failure early and initiate evidence-based management to limit progression and improve outcomes. Patients with heart failure may have other challenges managing their angina pectoris including medication adherence, economic implications, additional co-morbid conditions, increased adverse events, and other sequelae associated with mood disorders including depression. ${ }^{32}$

Sex difference plays a significant role in patients with MI. Assessment of baseline characteristics, medical history, clinical presentation at admission and treatment strategies suggests that women have a poorer long-term prognosis compared to men. Overall, significant heterogeneity was observed across clinical presentation and sex distribution in clinical and procedural variables. Our review showed that the rate of all-cause death and cardiac death were significantly higher in female than in male STEMI patient during a 2-year follow-up. ${ }^{24}$ However, there were no differences between sexes in all-cause or cardiac death in patients with NSTEMI and SIHD. Current ACS guidelines recommend that both sexes should be evaluated and treated the same. ${ }^{33}$ Despite this recommendation, men continue to receive more advanced therapeutic modalities than women. ${ }^{34}$ Although there were no differences in long-term mortality between men and women, women were generally older with more clustering of risk factors that may contribute to their higher mortality risk. Sex bias in treatment and sex disparities in vascular flow and structure may further add to this increased mortality. Most studies evaluating sex differences for prognosis found that women tend to have more concomitant vaso-vegetative symptoms masking chest pain, ${ }^{35}$ smaller vessel size, less collateral flow, more vascular stuffiness, and differences in remodeling. ${ }^{36}$ A greater awareness of the sex differences in presentation of angina pectoris between men and women is required by health care professionals to improve therapeutic strategies and outcomes in women. ${ }^{37}$

\section{Conclusion}

In view of the improved prognosis demonstrated for patients suffering from ACS, assessing outcomes in patients with angina pectoris represents a formidable task in modern

Table 4. Descriptive information of the other trials and subjects in this review.

\begin{tabular}{|c|c|c|c|c|c|c|c|}
\hline & Trial type & $\begin{array}{l}\text { Year of } \\
\text { publication }\end{array}$ & $\begin{array}{l}\text { Trial } \\
\text { name }\end{array}$ & $\begin{array}{l}\text { Number } \\
\text { of } \\
\text { patients }\end{array}$ & Study sites & $\begin{array}{l}\text { Age } \\
\text { (mean, } \\
\text { years) }\end{array}$ & $\begin{array}{l}\text { Male } \\
\text { percentage } \\
\text { (median) }\end{array}$ \\
\hline 1 & $\begin{array}{l}\text { Prospective, } \\
\text { observational } \\
\text { study }\end{array}$ & $\begin{array}{l}\text { 2013, } \\
\text { (Ref 22) }\end{array}$ & & 410 & $\begin{array}{l}\text { University } \\
\text { Hospital } \\
\text { Kralovske } \\
\text { Vinohrady }\end{array}$ & 67.2 & $69.3 \%$ \\
\hline 2 & $\begin{array}{l}\text { Randomized, } \\
\text { open-labeled } \\
\text { trial }\end{array}$ & $\begin{array}{l}\text { 2014, } \\
\text { (Ref 23) }\end{array}$ & Tailor & 923 & Denmark & 66 & $72 \%$ \\
\hline 3 & $\begin{array}{l}\text { Observational } \\
\text { registry }\end{array}$ & $\begin{array}{l}\text { 2014, } \\
\text { (Ref 24) }\end{array}$ & & 2533 & $\begin{array}{l}\text { A single center, } \\
\text { China }\end{array}$ & 57 & $63-80 \%$ \\
\hline
\end{tabular}


Table 5. Summary of acute coronary syndrome (ACS) prognosis factors outcomes, 2012-2017

Factor Outcomes

Mortality

STEMI

30 days

31 days to 2 years

NSTEMI and SIHD

2 years

Percutaneous Coronary Intervention $(\mathrm{PCl})$

Drug eluting stents (DES) versus bare metal stents (BMS)

Coronary artery bypass grafting (CABG)

Angina, Left Ventricular (LV) dysfunction and CAD

Heart failure and reduced ejection fraction (EF)

Angina and Heart Failure

Sex Differences

Exercise

Follow-up Strategies

Medications

Ranolazine

Intracoronary nicorandil

Danhog

Prasugrel and Clopidogrel

Nebivolol, Carvedilol, Metoprolol

High and Low Intensity Statins
Increased all cause morality

No difference in all-cause mortality

Higher mortality in NSTEMI group

Mortality and MACE higher in urgent versus delayed PCl group. No differences in mortality after hospitalization in PCI, NSTEMI and SIHD groups

Paclitaxel higher cardiac mortality and MI compared to sirolimus DES

High clinical risk: Greater benefit from DES

Low to moderate clinical risk: No difference between DES and BMS.

CABG group higher rate of resolution of angina symptoms compared to medical therapy alone.

Medically treated patients no correlation between resolution of angina and all-cause mortality.

No difference in all cause or CV mortality in heart failure with reduced EF.

LV dysfunction was associated with increased rate of hospitalization. Higher rate of impaired QoL and depression in patients less than 60 years with angina regardless of EF.

Women greater than 60 years of age had lower rate of CAD compared to men but more likely to have hypertension, dyslipidemia and family history of premature CAD.

Women less likely to have a positive stress test.

Supervised cyclic ergometer exercise increases functional capacity more than unsupervised walking.

Angina patients with reduced EF have more adverse outcomes despite improvement in exercise capacity with exercise training.

Comprehensive health care team approach resulted in greater adherence, reduced all cause and cardiac mortality, lower MACE and medical cost, longer survival and improved medication adherence compared to usual care.

No difference in ischemic-driven revascularization or hospitalization. No reduction in sudden cardiac death, cardiovascular death and MI.

No benefit.

Decreased inflammation or necrosis markers (Scd40L) and improvement in cardiac function.

No difference in MACE between prasugrel and clopidrogel.

MACE at 12 months lower in nebivolol $10 \mathrm{mg}$ daily vs. metoprolol $200 \mathrm{mg}$ daily. No difference between nebivolol and carvediol $25 \mathrm{mg}$ twice daily or carvediol and metoprolol.

High-intensity statin more effective than moderate intensity in reducing MACE.

Abbreviations: STEMI, ST segment elevation myocardial infarction; NSTEMI, non-ST segment elevation myocardial infarction; CAD, coronary artery disease; MACE, major adverse cardiovascular events; SIHD, stable ischemic heart disease; CV, cardiovascular; MI, myocardial infarction 
practice. The optimal diagnostic evaluation and treatment of patients suspected of having obstructive CAD remains unclear. LVEF, estimated glomerular filtration rate, and previous MI should be included in risk assessment tools for better prediction of prognosis. Our review reconfirms the importance that patients who receive follow-up care with comprehensive methods (pharmacist, patient education, primary care physicians, cardiologist) are more likely to adhere to medications, and a supervised cardiac rehabilitation exercise program that increases the functional capacity of coronary patients more than unsupervised walking. Given the high prevalence of CAD and excellent prognosis of symptomatic patients with contemporary care, larger randomized trials are still warranted to determine which therapies are the most effective to optimize therapy in the long term. Also, a therapeutic window with precise cut-offs for optimal therapy is warranted to find adequate balance between optimal treatment and those that are potentially detrimental and may result in adverse effects. We also recognize that the focus on randomized clinical trials with stringent inclusion and exclusion criteria often do not represent real world data. Registries, although they contain real world data, are limited by a lack of homogeneity, creating difficulties in drawing comparison between groups. Information regarding pre-enrollment screening (eg, screen failures) is often not reported in randomized controlled clinical trials. It is particularly relevant to report enrollment to screen ratio to provide the reader with the full view of the clinical trial and to inform the design of future clinical trials.

\section{References}

1. Task Force Members; Montalescot G, Sechtem U, Achenbach S, et al. 2013 ESC guidelines on the management of stable coronary artery disease: the Task Force on the management of stable coronary artery disease of the European Society of Cardiology. Eur Heart J. 2013;34(38):2949-3003.

2. Konigstein M, Giannini F, Banai S. The Reducer device in patients with angina pectoris: mechanisms, indications, and perspectives. Eur Heart J. 2018;39(11):925-933.

3. Rokos IC, Farkouh ME, Reiffel J, Dressler O, Mehran R, Stone GW. Correlation between index electrocardiographic patterns and pre-intervention angiographic findings: Insights from the HORIZONS-AMI trial. Catheter Cardiovasc Interv. 2012;79(7):1092-1098.

4. Puri R, Nissen SE, Shao M, et al. Coronary atheroma volume and cardiovascular events during maximally intensive statin therapy. Eur Heart J. 2013;34(41):3182-3190.

5. Ortega R, Garcia-Ortiz L, Torcal J, et al; ESCAP Group. Supervised exercise for acute coronary patients in primary care: a randomized clinical trial. Fam Pract. 2014;31(1):2029.

6. Rogers CA, Pike K, Campbell H, et al; CRISP investigators. Coronary artery bypass grafting in high-RISk patients randomised to off- or on-Pump surgery: a randomised controlled trial (the CRISP trial). Health Technol Assess. 2014;18(44):V-Xx, 1-157.

7. Ho PM, Lambert-Kerzner A, Carey EP, et al. Multifaceted intervention to improve medication adherence and secondary prevention measures after acute coronary syndrome hospital discharge: a randomized clinical trial. JAMA Intern Med. 2014;174(2):186-193.
8. Pilgrim T, Vranckx P, Valgimigli M, et al. Risk and timing of recurrent ischemic events among patients with stable ischemic heart disease, non-ST-segment elevation acute coronary syndrome, and ST-segment elevation myocardial infarction. Am Heart J. 2016;175:56-65.

9. Parikh KS, Coles A, Schulte PJ, et al. Relation of Angina Pectoris to Outcomes, Quality of Life, and Response to Exercise Training in Patients With Chronic Heart Failure (from HF-ACTION). Am J Cardiol. 2016;118(8):1211-1216.

10. Liu Z, Joerg H, Hao H, et al. Efficacy of High-Intensity Atorvastatin for Asian Patients Undergoing Percutaneous Coronary Intervention. Ann Pharmacother. 2016;50(9):725733.

11. Du L, Dong P, Jia J, et al. Impacts of intensive follow-up on the long-term prognosis of percutaneous coronary intervention in acute coronary syndrome patients - a single center prospective randomized controlled study in a Chinese population. Eur J Prev Cardiol. 2016;23(10):1077-1085.

12. Ozaydin M, Yucel H, Kocyigit S, et al. Nebivolol versus Carvedilol or Metoprolol in Patients Presenting with Acute Myocardial Infarction Complicated by Left Ventricular Dysfunction. Med Princ Pract. 2016;25(4):316-322.

13. Weisz G, Généreux P, Iñiguez A, et al; RIVER-PCI investigators. Ranolazine in patients with incomplete revascularisation after percutaneous coronary intervention (RIVER-PCI): a multicentre, randomised, double-blind, placebo-controlled trial. Lancet. 2016;387(10014):136-145.

14. Jolicœur EM, Dunning A, Castelvecchio S, et al. Importance of angina in patients with coronary disease, heart failure, and left ventricular systolic dysfunction: insights from STICH. J Am Coll Cardiol. 2015;66(19):2092-2100.

15. Gottlieb SS, Kop WJ, Ellis SJ, et al; HF-ACTION Investigators. Relation of depression to severity of illness in heart failure (from Heart Failure And a Controlled Trial Investigating Outcomes of Exercise Training [HF-ACTION]). Am J Cardiol. 2009;103(9):1285-1289.

16. Vassalli G, Klersy C, De Servi S, et al; BASKET-PROVE Investigators. Can the optimal type of stent be predicted based on clinical risk factors? A subgroup analysis of the randomized BASKET-PROVE trial. Am Heart J. 2016;173:17.

17. Kikuchi N, Jujo K, Yamaguchi J, Ogawa H, Hagiwara N. Impact of left ventricular ejection function on blood pressurelowering therapy in hypertensive patients with coronary artery disease. J Hypertens. 2016;34(5):1011-1018.

18. Hwang J, Lee HC, Kim BW, et al. The effect on periprocedural myocardial infarction of intra-coronary nicorandil prior to percutaneous coronary intervention in stable and unstable angina. J Cardiol. 2013;62(2):77-81.

19. Lv Y, Pan Y, Gao Y, et al. Effect of Danhong Injection Combined with Naoxintong Tablets on Prognosis and Inflammatory Factor Expression in Acute Coronary Syndrome Patients Undergoing Percutaneous Coronary Intervention. Acta Cardiol Sin. 2015;31(4):301-307.

20. Hemal K, Pagidipati NJ, Coles A, et al. Sex differences in demographics, risk factors, presentation, and noninvasive testing in stable outpatients with suspected coronary artery disease: Insights from the PROMISE Trial. JACC Cardiovasc Imaging. 2016;9(4):337-346.

21. D’Ascenzo F, Chieffo A, Cerrato E, et al. Incidence and Management of Restenosis After Treatment of Unprotected Left Main Disease With Second-Generation Drug-Eluting Stents (from Failure in Left Main Study With 2nd Generation Stents-Cardiogroup III Study). Am J Cardiol. 2017;119(7):978-982.

22. Paulu P, Osmancik P, Tousek P, et al. Lack of association between clopidogrel responsiveness tested using point-of-care assay and prognosis of patients with coronary artery disease. J Thromb Thrombolysis. 2013;36(1):1-6. 
23. Dridi NP, Johansson PI, Clemmensen P, et al. Prasugrel or double-dose clopidogrel to overcome clopidogrel lowresponse - The TAILOR (Thrombocytes And IndividuaLization of ORal antiplatelet therapy in percutaneous coronary intervention) randomized trial. Platelets. 2014;25(7):506-512.

24. Yao HM, Wan YD, Zhang XJ, et al. Long-term follow-up results in patients undergoing percutaneous coronary intervention $(\mathrm{PCI})$ with drug-eluting stents: results from a single high-volume PCI centre. BMJ Open. 2014;4(8):e004892.

25. Park HW, Yoon CH, Kang SH, et al; KAMIR/KorMI Registry. Early-and late-term clinical outcome and their predictors in patients with ST-segment elevation myocardial infarction and non-ST-segment elevation myocardial infarction. Int J Cardiol. 2013;169(4):254-261.

26. Chan MY, Sun JL, Newby LK, et al. Long-term mortality of patients undergoing cardiac catheterization for ST-elevation and non-ST-elevation myocardial infarction. Circulation. 2009;119(24):3110-3117.

27. Polonski L, Gasior M, Gierlotka M, et al; PL-ACS Registry Pilot Group. A comparison of ST elevation versus non-ST elevation myocardial infarction outcomes in a large registry database: are non-ST myocardial infarctions associated with worse long-term prognoses? Int J Cardiol. 2011;152(1):7077.

28. Zellweger MJ, Kaiser C, Jeger R, et al. Coronary artery disease progression late after successful stent implantation. J Am Coll Cardiol. 2012;59(9):793-799.

29. Stone GW, Maehara A, Lansky AJ, et al; PROSPECT Investigators. A prospective natural-history study of coronary atherosclerosis. N Engl J Med. 2011;364(3):226-235.

30. Dutta P, Courties G, Wei Y, et al. Myocardial infarction accelerates atherosclerosis. Nature. 2012;487(7407):325-329.

31. Fournier JA, Cabezón S, Cayuela A, Ballesteros SM, Cortacero JAP, Díaz De La Llera LS. Long-term prognosis of patients having acute myocardial infarction when $\leq 40$ years of age. Am J Cardiol. 2004;94(8):989-992.

32. Ziegelstein RC. Depression after myocardial infarction. Cardiol Rev. 2001;9(1):45-51.

33. Roffi M, Patrono C, Collet JP, et al; ESC Scientific Document Group. 2015 ESC Guidelines for the management of acute coronary syndromes in patients presenting without persistent ST-segment elevation: Task Force for the Management of Acute Coronary Syndromes in Patients Presenting without Persistent ST-Segment Elevation of the European Society of Cardiology (ESC). Eur Heart J. 2016;37(3):267-315.

34. Abbott JD, Vlachos HA, Selzer F, et al; National Heart, Lung, and Blood Institute Dynamic Registry. Gender-based outcomes in percutaneous coronary intervention with drugeluting stents (from the National Heart, Lung, and Blood Institute Dynamic Registry). Am J Cardiol. 2007;99(5):626631.

35. Milner KA, Funk M, Richards S, Wilmes RM, Vaccarino V, Krumholz HM. Gender differences in symptom presentation associated with coronary heart disease. Am J Cardiol. 1999;84(4):396-399.

36. Dey S, Flather MD, Devlin G, et al; Global Registry of Acute Coronary Events investigators. Sex-related differences in the presentation, treatment and outcomes among patients with acute coronary syndromes: the Global Registry of Acute Coronary Events. Heart. 2008;95(1):20-26.

37. Maas AHEM, Appelman YEA. Gender differences in coronary heart disease. Neth Heart J. 2010;18(12):598-603.

\section{Author Affiliations}

Fan Ye, MD; * † David Winchester, MD; + , Michael Jansen, MD; Arthur Lee, MD; $\$$ Burton Silverstein; $\oint$ Carolyn

Stalvey, MD Matheen Khuddus, MD; Joseph Mazza, $M D ; \|$ and Steven Yale, $M D+$

*Graduate Medical Education, University of Central Florida College of Medicine, Orlando, FL USA $\dagger$ Department of Internal Medicine, University of Central Florida College of Medicine, Orlando, FL USA $\$$ Department of Cardiology, University of Florida College of Medicine, Gainesville, FL USA

$\S$ The Cardiac and Vascular Institute, Gainesville, FL USA

ФDepartment of General Internal Medicine, University of Florida College of Medicine, Gainesville, FL USA

\|Marshfield Clinic Research Institute, Marshfield, WI USA 